\title{
PELOS CAMINHOS DA ASSISTÊNCIA ESTUDANTIL: PENSANDO SAÚDE MENTAL DO ESTUDANTE NA UERJ
}

\author{
THROUGH THE PATHS OF STUDENT ASSISTANCE: THINKING THE MENTAL \\ HEALTH OF STUDENTS AT UERJ
}

\author{
Rachel Alonso de Azevedo ${ }^{1}$ \\ Aline Passeri Dias ${ }^{2}$ \\ Cintia Rita de Oliveira Magalhães ${ }^{3}$ \\ Cíntia Moreira de Souza ${ }^{4}$ \\ Vinícius Anciães Darriba ${ }^{5}$
}

\begin{abstract}
RESUMO: O presente artigo tem como objetivo apresentar o trabalho desenvolvido pela equipe multiprofissional do DASPB - Departamento de Acolhida, Saúde psicossocial e bemestar, da UERJ - Universidade do Estado do Rio de Janeiro, e as reflexões precipitadas no cotidiano do serviço que levaram à construção das estratégias de cuidado no que tange à assistência estudantil da referida Universidade. Apresentam-se aqui as frentes de trabalho desenvolvidas no setor, tais como as salas de recepção, as rodas de conversa e as oficinas e discute-se a proposta de atuação de um departamento voltado à prevenção e promoção de saúde mental, na universidade, no âmbito da Pró-Reitoria de Políticas e Assistência Estudantis (PR-4) da UERJ. Além da apresentação do departamento e das ações desenvolvidas pela equipe, o artigo reflete sobre o papel dos setores de saúde mental nas universidades brasileiras, discutindo os problemas do enfoque individual, em detrimento das ações coletivas, bem como a patologização das demandas de atendimento.
\end{abstract}

Palavras-chave: Assistência Estudantil. Acolhimento. Saúde Mental. Ensino Superior.

\begin{abstract}
The present article proposes to present the work developed by the multiprofessional team at UERJ's (Universidade Estadual do Rio de Janeiro) DASPB Departamento de Acolhida, Saúde Psicossocial e Bem-estar (Hosting, Psycho-social Health

\footnotetext{
1 Pedagoga e diretora do DASPB - Departamento de Acolhida Saúde psicossocial e Bem-estar da UERJ Universidade do Estado do Rio de Janeiro, mestre em Educação pela UNIRIO - Universidade Federal do Estado do Rio de Janeiro e doutoranda em educação pela UNIRIO. ORCID: 0000-0003-2934-4993. E-mail: rachel.azevedo@uerj.br.

${ }^{2}$ Psicóloga do DASPB - Departamento de Acolhida Saúde psicossocial e Bem-estar da UERJ - Universidade do Estado do Rio de Janeiro. Mestre em Psicologia Social pelo Programa de Pós-Graduação em Psicologia Social da UERJ. Terapeuta Cognitivo-Comportamental. Professora Assistente e Supervisora da Universidade Estácio de Sá. ORCID: 0000-0001-6673-4080. E-mail: alinepasseri@gmail.com.

${ }^{3}$ Psicóloga do DASPB - Departamento de Acolhida Saúde psicossocial e Bem-estar da UERJ - Universidade do Estado do Rio de Janeiro. Psicanalista. Mestre em Teoria Psicanalítica pela UFRJ. Especialista em Psicanálise e Saúde Mental pela UERJ. ORCID: 0000-0002-6495-6648. E-mail: cintia.magalhaes@uerj.br.

${ }^{4}$ Psicóloga do DASPB - Departamento de Acolhida Saúde psicossocial e Bem-estar da UERJ - Universidade do Estado do Rio de Janeiro. Mestranda em Atenção Psicossocial no Instituto de Psiquiatria da Universidade Federal do Rio de Janeiro. Especialista em Psicologia Clínica pelo IFEN (Instituto de Psicologia Fenomenológico-Existencial do Rio de Janeiro). ORCID: 0000-0003-1268-7332. E-mail: cintia.souza@uerj.br.

${ }^{5}$ Professor Associado do Instituto de Psicologia da Universidade do Estado do Rio de Janeiro. Coordenador Técnico do DASPB - Departamento de Acolhida Saúde psicossocial e Bem-estar da UERJ - Universidade do Estado do Rio de Janeiro. ORCID: 0000-0002-9986-6554. E-mail: viniciusdarriba@gmail.com.
} 
and Wellness Department) and the considerations raised as consequence of services routinely provided that led to the development of strategies for student care as it pertains to Student Assistance at the University in question. We present work fronts developed at the Department, such as hosting groups, "talk rounds" and workshops, as well as discuss the proposed mission of a department aiming for prevention and promotion in the mental health area at University, in the context of the Pro-Rectory of Student Affairs and Policies (PR-4) at UERJ. Besides presenting the department and the initiatives developed by the team, this article reflects on the role of mental health departments in brazillian universities, discussing the problems inherent to actions with individual focus, at the expense of collective ones, as well as the pathologization of the demands present.

Key-words: student aid, fostering, mental health, higher learning

\section{INTRODUÇÃO}

A história da Assistência Estudantil no Brasil tem uma longa trajetória. Seu marco inaugural é a instalação da Casa do Estudante Brasileiro no Rio de Janeiro no início dos anos 1930 (COSTA, 2010 apud IMPERATORI, 2017). De lá para cá, uma série de outras ações foram criadas, porém foi com a implantação do REUNI - Programa de Apoio a Planos de Reestruturação e Expansão das Universidades Federais (BRASIL, 2007) e do PNAESPrograma Nacional de Assistência Estudantil (BRASIL, 2010), que ações de ampliação, interiorização, reestruturação, apoio e assistência foram efetivamente desenvolvidas e consolidadas com base em uma política nacional voltada às Instituições Federais de Ensino Superior (IFES).

Dentre as propostas do Reuni em relação ao acesso e permanência do estudante na universidade, destacam-se no artigo 2, alíneas I e V, a preocupação com a redução das taxas de evasão, a ocupação das vagas ociosas e o aumento das vagas de ingresso, especialmente no período noturno, além da ampliação de políticas de inclusão e assistência estudantil (BRASIL, 2007; AZEVEDO, 2019). Já o PNAES é considerado um instrumento de consolidação do REUNI no que diz respeito à normatização das ações de assistência estudantil a serem desenvolvidas pelas IFES e tem por objetivo principal a ampliação das condições de permanência dos jovens na educação superior pública federal, visando o atendimento prioritário, mas não exclusivo, de estudantes oriundos da rede pública de educação básica ou 
com renda familiar per capita de até um salário mínimo e meio, ou seja, aqueles em situação de vulnerabilidade socioeconômica. (CARVALHO, 2016; BRASIL, 2010).

O PNAES, entretanto, destina-se somente às instituições federais de ensino ou às estaduais que aderiram ao SISU (Sistema de Seleção Unificada). Nesse caso, a UERJ, instituição em pauta, não se encontra subordinada ao Plano, apesar de ter sido a primeira universidade brasileira, doze anos antes das federais, em 2002, a implantar, por lei estadual (Lei $\mathrm{n}^{\circ}$ 3.524/2000), o sistema de reserva de vagas com o objetivo de democratizar o acesso à universidade pública (UERJ, 2020).

O Proiniciar (Programa de Iniciação Acadêmica dos Cursos de Graduação), criado em 2004, foi uma das ações que objetivaram a assistência e permanência dos estudantes de graduação da UERJ, no que diz respeito à garantia da bolsa de permanência entre outros benefícios oferecidos, com particular atenção aos ingressantes pelas políticas de ações afirmativas. O setor orienta os estudantes ingressantes por reserva de vagas na emissão do passe livre universitário (Decreto $\mathrm{n}^{\circ} 38.280 / 2014$ ), viabiliza a aquisição de material didático sugerido pela unidade acadêmica, oferece disciplinas, oficinas, eventos culturais e disponibiliza a bolsa de permanência do estudante, no valor de quinhentos reais (SOUZA, 2016; UERJ, 2020; UERJ, 2018). Além dos benefícios oferecidos pelo Proiniciar, a universidade passou a contar, em 2011, com um restaurante universitário, que é mais uma ação de assistência estudantil garantidora da permanência qualificada dos estudantes na universidade.

Apesar desse pioneirismo, a UERJ instituiu somente em março de 2020 a Pró-Reitoria de Políticas e Assistência Estudantis (PR-4), que tem por objetivo consolidar e ampliar as ações de assistência antes vinculadas à Pró-Reitoria de Graduação - PR-1, antiga SR-1 (Sub-Reitoria de Graduação). Com a criação, na UERJ, de uma Pró-Reitoria dedicada a formular e desenvolver políticas e ações voltadas à assistência estudantil, novas demandas de assistência para além do atendimento às demandas de ordem objetiva (suporte pecuniário, garantia à alimentação e ao transporte etc.) têm se tornado uma crescente reivindicação estudantil, tal como a atenção à saúde (física e emocional) e o apoio pedagógico. É nesse contexto que é criado, na PR-4, o Departamento de Acolhida, Saúde psicossocial e bem-estar (DASPB), originário do Núcleo de Acolhida ao Estudante da UERJ (NACE), anteriormente vinculado à antiga SR-1 - Sub-Reitoria de Graduação da UERJ.

O DASPB é um departamento voltado para o atendimento do corpo discente, na interseção do campo da saúde e da educação, promovendo a construção de estratégias que fortaleçam a assistência estudantil na UERJ. É formado por uma equipe multidisciplinar com 
psicólogas, assistente social e pedagoga e tem como propósito constituir uma rede de cuidado que atenda aos estudantes de graduação, pós-graduação e colégio de aplicação da UERJ.

Neste sentido, o presente artigo tem como objetivo apresentar o trabalho desenvolvido pela equipe multiprofissional do DASPB/UERJ e as reflexões precipitadas em seu cotidiano, que levaram à construção das estratégias e ações aqui apresentadas.

\section{O Departamento de Acolhida, Saúde psicossocial e bem-estar (DASPB)}

O DASPB tem por missão fortalecer e promover a permanência com qualidade na Universidade, por intermédio do fomento de ações de acolhida, cuidado e bem-estar no ambiente universitário, nos moldes do que já vem sendo feito nas universidades federais com a regulamentação do PNAES.

Sabe-se que, ao longo das últimas décadas, o espaço universitário vem sofrendo um processo de heterogeneização. As políticas afirmativas de acesso à universidade possibilitaram que o espaço, outrora elitizado e distante de parte considerável da população, se tornasse um ambiente plural com a entrada de jovens negros, estudantes provenientes de escolas públicas, pertencentes aos estratos sociais mais desfavorecidos, e os ditos alunos trabalhadores. Essa nova realidade universitária também demandou respostas políticas. A UERJ, por exemplo, começou a ampliar e consolidar a discussão sobre o papel da assistência estudantil e a integração dos diferentes serviços envolvidos, com a criação da PR-4, como dito anteriormente.

Nesse contexto, a proposta do DASPB é promover a articulação dos serviços internos, bem como de parcerias externas, para a construção de estratégias que fortaleçam a assistência em saúde na UERJ, em especial a saúde mental, criando assim maior rede de apoio e cuidado aos estudantes da universidade. Ao fazer essa costura, abre-se a possibilidade de buscar novos caminhos diante do sofrimento, evitando explicações simplistas que fragmentam as ações e, muitas vezes, levam a um discurso de patologização dos sentimentos, medicalização da vida e favorecimento dos autodiagnósticos (CFP, 2015).

O DASPB, por conseguinte, configura-se como um setor dentro da assistência estudantil voltado para a assistência à saúde mental e promoção de ações de acolhida e bemestar, o que engloba a atuação multidisciplinar nas áreas psicológica, social e pedagógica. Por essa característica, seu trabalho abrange ações no nível da política e das estratégias em saúde mental, já que é o agente institucional melhor habilitado a construir junto à universidade a política de assistência estudantil no campo da saúde mental. Os eixos de trabalho do DASPB 
orientam a sequência da discussão no que diz respeito à estratégia de trabalho e às ações de assistência no âmbito da saúde mental dos estudantes.

\section{O acolhimento e a urgência subjetiva como estratégias de atuação do DASPB}

O DASPB, na perspectiva da assistência estudantil, visa desenvolver ações de promoção da saúde mental dos estudantes, não se limitando ao atendimento e à escuta psicológica, mas sim atuando na promoção da saúde mental no espaço universitário, permitindo a articulação entre os diferentes agentes institucionais e a sinergia das iniciativas. Para tanto, as ações do setor são norteadas por dois eixos principais: a noção de acolhimento ampliado, não apenas como serviço especializado, e o atendimento a demandas estudantis a partir do dispositivo da urgência subjetiva.

Em relação ao acolhimento, tradicionalmente essa palavra tem sido amplamente empregada no campo da saúde, ora como uma dimensão espacial, se traduzindo em recepção administrativa e ambiente confortável, ora como uma ação de triagem administrativa e repasse de encaminhamentos para serviços especializados.

Tais definições, entretanto, quando tomadas isoladamente dos processos de trabalho em saúde, se restringem a uma ação pontual, isolada e descomprometida com processos de responsabilização e produção de vínculo (MINISTÉRIO DA SAÚDE, 2013). É fundamental que o acolhimento envolva um conjunto de elementos que vão desde os saberes que subsidiam o atendimento individual em saúde até a maneira como as equipes interagem na organização do processo de trabalho, exigindo a agregação de novos atores capazes de se envolver com a gestão do cuidado. De acordo com o Ministério da Saúde (2008), o acolhimento é:

uma diretriz da Política Nacional de Humanização (PNH), que não tem local nem hora certa para acontecer, nem um profissional específico para fazê-lo: faz parte de todos os encontros do serviço de saúde. O acolhimento é uma postura ética que implica na escuta do usuário em suas queixas, no reconhecimento do seu protagonismo no processo de saúde e adoecimento, e na responsabilização pela resolução, com ativação de redes de compartilhamento de saberes. (MINISTÉRIO DA SAÚDE, 2008).

Pode-se dizer, genericamente, que o acolhimento é uma prática que deve estar presente em todas as relações de cuidado, nos encontros reais entre quem atende e quem é atendido, nos atos de receber e escutar as pessoas, podendo acontecer de formas variadas.

Em sua estrutura de criação e funcionamento, o DASPB tem a proposta do acolhimento como estratégia de atenção aos estudantes da UERJ. Um acolhimento que se dá, 
entretanto, não em um espaço de saúde, mas em um espaço educativo, o que implica uma gestão do cuidado que exige a articulação com outras instâncias e outros atores institucionais.

No caso da UERJ, a grande maioria dos que buscam atendimento no DASPB se veem tomados por um mal-estar agudo que tende a se dissipar ao longo de alguns encontros. A chegada ao setor, porém, costuma ser marcada por um caráter de urgência. Este é proveniente não só do sujeito em sofrimento, mas também da própria demanda institucional. É comum que os estudantes sejam trazidos por terceiros, encaminhados por professores ou outros setores da universidade com o pedido de acolhimento urgente desta dor que parece afligir não só aquele que a carrega, como também quem está a seu redor, conferindo um tom emergencial a essas situações que podem ser definidas como urgências subjetivas (CALAZANS e BASTOS, 2008). Estas se desdobram em dois pontos: no fenômeno, que como descrito acima, envolve uma certa perturbação do social e leva o sujeito, encaminhado ou por conta própria, a buscar ajuda; e em um dispositivo clínico institucional de acolhimento de sujeitos em "crise". A adoção desse dispositivo tem permitido uma espécie de decantação da demanda que, na maioria das vezes, não resulta em tratamento. Não há pressa em responder, a fim de se evitar uma ação protocolar ou prescritiva. O que se busca é oferecer um espaço de escuta que acolhe o sujeito nesse momento de crise, cuidando para não "responder a urgência com outra urgência". (MALAJOVICH et al, 2017).

Nessa perspectiva, os acolhimentos realizados no DASPB, a partir da lógica da urgência subjetiva, têm a proposta de desconstruir essa urgência, que se apresenta travestida, na maioria das vezes, de emergência médica, de forma que o profissional que recebe o "estudante em crise" possa se demorar nessa escuta e explorar, ao longo dos acolhimentos, os sofrimentos e queixas que levaram o estudante a buscar atendimento no setor.

Desse modo, o conceito de urgência subjetiva aqui tratado não está relacionado ao atendimento de demandas médicas, na medida em que entendemos que o DASPB não é um espaço destinado ao atendimento de situações de gravidade médica que demandem atendimento em hospitais de emergência, tal como nos casos de abertura de surto e passagens ao ato. Assim sendo, faz-se necessário discutirmos e verificarmos as possibilidades de articulação e encaminhamento para a rede pública de saúde, dos casos de maior gravidade, tal como urgências psiquiátricas, por entendermos que cabe ao Sistema Único de Saúde (SUS) a assistência integral à saúde. Acreditamos, pois, que os setores de atendimento à saúde do estudante, na assistência estudantil, são promotores de saúde e bem-estar nas instituições de 
ensino, além de articuladores das demandas que necessitam de encaminhamento para a rede pública de saúde e não substitutos de uma estrutura pública de saúde já existente.

\section{A criação do setor e a atuação multidisciplinar na assistência estudantil}

Desde o ano de 2019, o trabalho no setor vem sendo repensado e reestruturado, o que se tornou mais premente com a criação da PR-4 em 2020. Para compreendermos melhor o caminho percorrido até aqui, faz-se necessária uma breve retrospectiva do surgimento do setor e das modificações sofridas até sua recente incorporação à PR-4.

O atual DASPB surgiu como NACE (Núcleo de Acolhida ao Estudante), em 2011, instituído por ato administrativo 032/2011 (UERJ, 2011). O núcleo estava diretamente vinculado à Reitoria da Universidade e teve origem por intermédio do Programa de extensão UERJ pela Vida, criado em 2008, com o objetivo inicial de investigar o número de suicídios ocorridos na instituição, os fatores precipitantes do suicídio no ambiente universitário e o público-alvo envolvido nesses episódios, visando à promoção de ações de prevenção dentro e fora da universidade (AZEVEDO, 2019).

Em sua criação, o NACE tinha como público alvo toda a comunidade universitária, em especial os estudantes, tendo como foco a prevenção dos eventos de suicídio. Em 2019, entretanto, ele desvinculou-se do Programa UERJ pela Vida e da Reitoria e foi integrado à antiga SR-1, através da revogação e alteração de seu ato executivo de criação 014/2019 (UERJ, 2019), o que deslocou o foco de atuação do setor da prevenção do suicídio para a assistência estudantil:

com vista a prestar assistência estudantil e promover a saúde do estudante, problematizando o sofrimento desencadeado e/ou apresentado no ambiente universitário, através da articulação entre os diferentes atores da comunidade acadêmica, afins com este objetivo (UERJ, 2019).

Por meio da criação da PR-4 em 2020, e incorporação do antigo NACE, agora DASPB, à estrutura de assistência estudantil da UERJ, foi possível definir e organizar com mais clareza a condução do trabalho na perspectiva da assistência estudantil, voltada para a promoção da saúde e o bem-estar do corpo discente.

Em relação à estrutura de trabalho, as ações no antigo NACE estavam dirigidas principalmente para o acolhimento individualizado. Os acolhimentos duravam alguns encontros, que tinham ou não desdobramentos posteriores, como encaminhamentos para a 
rede pública de saúde, para o Serviço de Psicologia Aplicada da universidade (SPA), para atendimentos pedagógicos ou sociais individuais com os profissionais da própria equipe, dentre outros.

Muitas vezes os atendimentos realizados no serviço ocorriam no formato de pronta escuta ou plantão psicológico, ou seja, era realizado um primeiro acolhimento do estudante no ato da chegada ao setor, sem nenhum tipo de agendamento prévio. Em outros momentos, os profissionais eram demandados institucionalmente para o atendimento imediato de casos considerados urgentes, desde o atendimento a estudantes chorando nos corredores da Universidade até a intermediação da equipe em situações de crises psiquiátricas e tentativas de suicídio.

A partir de 2019, a equipe passou a repensar o alcance, viabilidade e objetivo dos atendimentos individuais realizados e estruturar uma ampliação da proposta de trabalho pautada em ações de cuidado e bem-estar coletivas, visando não só ao alcance de um número maior de estudantes, mas principalmente à promoção de um cuidado ampliado, que leva em consideração os aspectos culturais, políticos, sociais, institucionais e singulares vivenciados por cada aluno que nos procura.

Voltando-nos mais uma vez para a concepção ampliada de saúde, entendemos que esta, como preconizada pela Organização Mundial de Saúde (OMS), é “um estado de completo bem-estar físico, mental e social e não somente a ausência de afecções e enfermidades (...) é mais um valor da comunidade que do indivíduo.” Assim sendo, o DASPB tem como proposta a promoção ampliada de saúde na universidade, por compreendermos que o cuidado com a saúde do estudante, especialmente a saúde mental, engloba questões que perpassam diversas dimensões, como o bem-estar físico, mental, social e pedagógico dos estudantes atendidos no setor (USP, 2020; AZEVEDO, 2019).

Assim, por compreendermos que o trabalho de promoção de saúde mental na universidade perpassa questões multifatoriais e complexas, os profissionais do DASPB valorizam e defendem a composição e atuação multidisciplinar da equipe, a partir da articulação do trabalho de diferentes profissionais, tais como: psicólogos, assistentes sociais e pedagogos que desenvolvem as ações de forma articulada e integrada.

As psicólogas do DASPB, por exemplo, integram as estratégias de promoção à saúde mental, atuando frente às situações de sofrimento psíquico desencadeado e/ou apresentado no ambiente universitário. Dentre as atividades empreendidas estão os acolhimentos individuais 
integrados aos alunos, sempre no modelo interconsulta, bem como atividades realizadas em equipe interdisciplinar.

Já a pedagoga do setor é responsável pelo atendimento de demandas relacionadas a dificuldades no curso, problemas com os trâmites administrativos da UERJ, dificuldades relativas à organização para os estudos e demandas relativas à necessidade de interface com diversos setores da Universidade, que possam auxiliar na resolução da problemática em questão, além da proposição de ações multidisciplinares como rodas de conversa e oficinas.

O serviço social atua na identificação de questões sociais ou atinentes a direitos, como as de previdência e assistência social, sendo responsável também pela integração com as políticas sociais públicas e institucionais que possam auxiliar na resolução da demanda trazida, além de participar da proposição de ações multidisciplinares como rodas de conversa e oficinas.

Em relação às ações integradas e articuladas de cuidado desenvolvidas no setor, destacamos que essas estão divididas em três frentes principais: as salas de recepção, as rodas de conversa e as oficinas.

A sala de recepção ou grupo de recepção se constitui atualmente na porta de entrada única para os atendimentos no DASPB. É realizada duas vezes por mês em dias e horários previamente definidos e divulgados no site para as faculdades e institutos. São oito vagas por grupo e o critério para definir quem as ocupará é a ordem de chegada. A proposta desse dispositivo é possibilitar que as questões trazidas pelos estudantes, na maioria das vezes vivenciadas de forma solitária por cada um, possam ser compartilhadas e conduzidas nesses grupos de acolhimento, com vistas a favorecer o compartilhamento de experiências, a integração entres eles e a implicação dos estudantes em seu cuidado.

Em paralelo à sala de recepção, o DASPB conta também com o dispositivo das oficinas, que tem por objetivo trabalhar, de forma prática, um conceito, conteúdo ou habilidade específica a ser desenvolvida pelos estudantes em sua rotina acadêmica, a partir do levantamento e análise das demandas que chegam ao setor, tais como: organização dos estudos; gestão e organização do tempo no contexto acadêmico; técnicas de estudo; técnicas de apresentação; habilidades sociais, manejo da ansiedade etc.

A terceira frente é a das rodas de conversa temáticas intituladas "Ser-Universitário". Essas consistem em espaços de construção coletiva e troca de experiências entre os estudantes acerca de determinada temática que perpassa suas vivências no cotidiano universitário. As rodas acontecem uma vez por mês e contam com duas profissionais que atuam como mediadoras e facilitadoras do processo. 


\section{CONSIDERAÇÕES FINAIS}

Olhar para a saúde mental ao ofertar assistência estudantil tem se mostrado extremamente importante. Contudo, criar espaços comprometidos com o cuidado e o acolhimento de alunos em sofrimento psíquico possui a complexidade de uma equação composta por inúmeras variáveis. Estar em um ambiente voltado para formação profissional localiza esse cuidado em um campo diferenciado e exige uma composição de equipe de trabalho que não pode se centrar, exclusivamente, em profissionais clínicos. Em outras palavras, estar dentro de uma Universidade não é o mesmo que estar em um ambulatório ou hospital. Essa particularidade caracteriza a práxis em um entre, ou seja, por um ponto de interseção entre a saúde e a educação que precisa ser levado em conta na construção do trabalho realizado no DASPB.

Em tempos de pouca ou nenhuma tolerância ao sofrimento, à ansiedade e ao mal-estar, trazer uma proposta cujo foco não seja responder às urgências de forma imediata, transformando-as em emergências, torna-se fundamental. Ter como horizonte a noção de que as vivências e processos que os alunos atravessam ao longo de sua trajetória acadêmica precisam ser questionados e pensados como fazendo parte de um contexto mais amplo, nos afasta de uma perspectiva perigosa e simplista de medicalização da educação. Esse fenômeno poderia ter consequências sérias como intensificar os processos de exclusão já tão conhecidos. Se desejarmos incluir aqueles que historicamente foram excluídos, apartados do ensino superior, é preciso que estejamos atentos para não transformarmos sofrimentos que têm sua origem em problemas sociais, econômicos e políticos, por exemplo, em doenças, transtornos e distúrbios, tomando cuidado para não perpetuarmos e ampliarmos a exclusão dentro do ambiente universitário, a partir de um discurso de inclusão que individualize questões e problemas institucionais e coletivos.

\section{REFERÊNCIAS}

AZEVEDO, R. A. O acolhimento estudantil: estudantes universitários em sofrimento e desalinho. 2019. 223 p. Dissertação (Mestrado em Educação) - Programa de Pós-graduação da Universidade Federal do Estado do Rio de Janeiro - UNIRIO, Rio de Janeiro, 2019. 
BRASIL, Decreto $\mathrm{n}^{\circ}$ 6.096, de 24 de abril de 2007. Programa de Apoio a Planos de Reestruturação e Expansão das Universidades Federais - REUNI, Brasília, DF, abr., 2007. Disponível em: http://www.planalto.gov.br/ccivil_03/_Ato20072010/2007/Decreto/D6096.htm. Acesso em: 14 ago. 2020.

BRASIL, Decreto $n^{\circ}$ 7.234, de 19 de julho de 2010. Plano Nacional de Assistência Estudantil - PNAES, 2010. Disponível em: http://www.planalto.gov.br/ccivil_03/_ato20072010/2010/decreto/d7234.htm. Acesso em: 25 out. 2019.

CALAZANS, R., BASTOS. A. Urgência subjetiva e clínica psicanalítica. Rev latinoam. psicopatol. fundam. São Paulo, v. 11, n. 4, p. 640-652, dezembro 2008. Disponível em: http://www.scielo.br/scielo.php?script=sci_arttext\&pid=S1415$47142008000400010 \& \operatorname{lng}=$ en\&nrm=iso. Acesso em: 13 out. 2019

CARVAlHO, M. V. Tão perto e tão longe dos Jardins de Epicuro: memória social e violência sutil. Um olhar sobre os alunos de origem popular nas universidades públicas brasileiras. 2016. 137p. Tese (Doutorado em Memória Social), Programa de Pós-graduação em Memória Social - Universidade Federal do Estado do Rio de Janeiro - UNIRIO, Rio de Janeiro, 2016.

CFP - CONSELHO FEDERAL DE PSICOLOGIA. Recomendações de práticas não medicalizantes para profissionais e serviços de educação e saúde: grupo de trabalho educação e saúde do fórum sobre medicalização da educação e saúde. 1 ed. São Paulo, 2015. Disponível em: https://site.cfp.org.br/wpcontent/uploads/2015/06/CFP_CartilhaMedicalizacao_web-16.06.15.pdf. Acesso em 13 out. 2019.

IMPERATORI, T. K. A trajetória da assistência estudantil na educação superior brasileira. Rev. Serv. Soc. Soc., São Paulo, n. 129, p. 285-303, maio/ago., 2017. Disponível em: https://www.scielo.br/pdf/sssoc/n129/0101-6628-sssoc-129-0285.pdf. Acesso em: 31 ago. 2020.

MALAJOVICH, N. et al. A juventude universitária na contemporaneidade: a construção de um serviço de atenção em saúde mental para estudantes. Rev. Mental, Barbacena, v.11 n.21, jul./dez., p. 356-377, 2017. Disponível em: http://pepsic.bvsalud.org/pdf/mental/v11n21/v11n21a05.pdf. Acesso em 13 out. 2019.

MINISTÉRIO DA SAÚDE, Biblioteca Virtual em Saúde: Dicas em Saúde - Acolhimento, 2008. Disponível em: http://bvsms.saude.gov.br/bvs/dicas/167acolhimento.html. Acesso em: 19 nov. 2019.

MINISTÉRIO DA SAÚDE. Política Nacional de Humanização - PNH, 1 ed. Brasília, 2013. Disponível em: http://bvsms.saude.gov.br/bvs/publicacoes/politica_nacional_humanizacao_pnh_folheto.pdf. Acesso em 25 out. 2019. 
VILANOVA, A., TENENBAUM, D., MUÑOZ, N. M. Do grupo ao laço: o mal-estar na juventude e suas modulações. Revista Affectio Societatis, Medellín, Colombia, v. 15, n. 28, p. 60-80.

https://revistas.udea.edu.co/index.php/affectiosocietatis/article/view/328014/20787001.

Acesso em: 20 ago. 2020.

SOUZA, A. C. S. Sistema de cotas na UERJ: uma abordagem sobre a demanda de inscritos.

Rev. Eletrônica do Vestibular, ano 9, n.25, 2016. Disponível em: http://www.revista.vestibular.uerj.br/artigo/artigo.php?seq_artigo=44. Acesso em: 26 mar. 2018.

USP - UNIVERSIDADE DE SÃO PAULO, Biblioteca Virtual de Direitos Humanos: Constituição da Organização Mundial de Saúde (OMS/WHO) - 1946, c2020. Disponível em: http://www.direitoshumanos.usp.br/index.php/OMS-Organiza $\% \mathrm{C} 3 \% \mathrm{~A} 7 \% \mathrm{C} 3 \% \mathrm{~A} 3 \mathrm{O}-$ Mundial-da-Sa\%C3\%BAde/constituicao-da-organizacao-mundial-da-saude-omswho.html. Acesso em 01 set. /2020.

UERJ - UNIVERSIDADE DO ESTADO DO RIO DE JANEIRO, Ato Executivo 032/Reitoria/2011. Instituição do Núcleo de Acolhida ao Estudante (NACE), 2011. Disponível em: http://www.boluerj.uerj.br/pdf/aeda_00322011_21092011.pdf. Acesso em: 23 set. 2020.

UERJ - UNIVERSIDADE DO ESTADO DO RIO DE JANEIRO, Ato Executivo 014/Reitoria/2019. Revogação da AEDA 032/2011 e nova redação do Núcleo de Acolhida ao Estudante (NACE), 2019. Disponível em: http://www.boluerj.uerj.br/pdf/aeda_00142019_15052019.pdf. Acesso em: 23 set. 2020.

UERJ - UNIVERSIDADE DO ESTADO DO RIO DE JANEIRO, Departamento de Articulação, Iniciação Acadêmica e de Assistência e Inclusão Estudantil: Relatório Sucinto de Atividades da Coordenadoria de Articulação e Iniciação Acadêmica, 2018. Disponível em: http://www.daiaie.uerj.br/documentos/Relatorio2018.pdf. Acesso em: 19 ago. 2020.

UERJ - UNIVERSIDADE DO ESTADO DO RIO DE JANEIRO, Departamento de Articulação, Iniciação Acadêmica e de Assistência e Inclusão Estudantil: Proiniciar, c2020. Disponível em: http://www.daiaie.uerj.br/index.php/proiniciar/. Acesso em: 19 ago. 2020.

UERJ - UNIVERSIDADE DO ESTADO DO RIO DE JANEIRO, Departamento de Articulação, Iniciação Acadêmica e de Assistência e Inclusão Estudantil: Programa de Ação Afirmativa, c2020. Disponível em: http://www.daiaie.uerj.br/index.php/programa-de-acaoafirmativa/. Acesso em 28 ago. 2020. 